\title{
Clinical Characteristics of Familial Generalized ANXIETY DisORDER
}

\author{
Kenneth S. Kendler, Michael C. Neale, Ronald C. Kessler, Andrew C. Heath, \\ and Lindon J. Eaves
}

\begin{abstract}
The authors seek to determine whether the clinical characteristics of generalized anxiety disorder (GAD) differ in individuals with a bigh vs. low familial vulnerability to illness. We identified 486 personally interviewed female twins from a population-based register who bad both an interviewed co-twin and a lifetime bistory of GAD using modified DSM-III-R criteria which required a one-month minimum duration of illness. We attempted to predict risk for $G A D$ in the co-twin from the clinical features of the GAD in the proband twin using the Cox proportional bazard model, controlling for year of birtb and zygosity. Only two variables uniquely predicted an increased risk for $G A D$ in the co-twin: number of GAD symptoms endorsed and comorbidity with bulimia. Variables that did not uniquely predict risk of illness in the co-twin included age at onset, duration of the longest episode and number of episodes. The familial vulnerability to GAD can be meaningfully indexed by clinical features of the syndrome. These results suggest that if the syndrome of $G A D$ is to be narrowed, it would, from a familial perspective, be more valid to increase the minimum number of required symptoms ratber than to increase the minimum duration of illness. Anxiety 1:186-191 (1994/1995). @ 1995 Wiley-Liss, Inc.
\end{abstract}

Key words: anxiety, family studies, generalized anxiety disorder, comorbidity, twin studies

\section{INTRODUCTION}

\begin{abstract}
A lthough generalized anxiety disorder (GAD) was formally proposed as a diagnostic category less than 20 years ago (Spitzer et al., 1975; Brown et al., 1994), the criteria for this disorder have, during this period, been revised many times. The minimum duration of illness has variously been set at two weeks (Spitzer et al., 1975), one month (American Psychiatric Association, 1980) or six months (American Psychiatric Association, 1987). The minimum number of required symptoms has varied from one out of five (Spitzer et al., 1975), at least one from three of four groups (American Psychiatric Association, 1980), six out of eighteen (American Psychiatric Association, 1987) and most recently, to three out of six (American Psychiatric Association, 1994). Various diagnostic hierarchies have also been applied to GAD, ranging from excluding GAD syndromes when they are "due to" another mental disorder (American Psychiatric Association, 1980 ) or excluding cases which meet criteria only during episodes of psychotic or mood disorders (American Psychiatric Association, 1987, 1994) or only when also meeting criteria for a psychotic dis-
\end{abstract}

order, a mood disorder, Briquet's syndrome or panic disorder (Spitzer et al., 1975).

Although concern has been expressed about the validity of GAD as a diagnostic category (Barlow et al., 1986; Breslau et al., 1987; Breier et al., 1985; Brown et al., 1994), few studies have explicitly attempted to validate diagnostic criteria for this disorder. Breslau and Davis (1985), for example, found that a six-month minimum duration of illness may more confound than improve the descriptive validity of GAD.

\footnotetext{
Department of Psychiatry (K.S.K., L.J.E.) and the Department of Human Genetics (K.S.K., A.C.H., M.C.N., L.J.E.), Medical College of Virginia/Virginia Commonwealth University, Richmond, Virginia; the Institute for Social Research, University of Michigan, Ann Arbor, Michigan (R.C.K.); and the Department of Psychiatry, Washington University School of Medicine, St. Louis, Missouri (A.C.H.).
}

Received for publication October 6, 1994; revised December 23 , 1994; accepted December 27, 1994.

Address reprint requests to K.S. Kendler, M.D., Department of Psychiatry, MCV/NCU, Box 980710, Richmond, VA 23298-0710. 
Familial aggregation remains one of the most important validating criteria for psychiatric disorders (Robins and Guze, 1970). In this report, we examine results from a population-based study of female twins to determine the clinical characteristics of GAD that predict familial aggregation.

\section{SAMPLE}

\section{METHODS}

Characteristics of this sample have been outlined previously (Kendler et al., 1992a). In brief, this sample of Caucasian female same-sex twins, born from 1934 to 1971, was obtained from the population-based Virginia Twin Registry, formed from a systematic review of birth records in the Commonwealth of Virginia from 1915 onward. Twins were eligible to participate if both members of the pair responded to a mailed questionnaire, the response rate to which was approximately $64 \%$. Of the 2,352 individuals from 1,176 twin pairs who met these criteria, we succeeded in personally interviewing 2,163 (92.0\%) of them, including both members of 1,033 pairs. Of the completed interviews, $89.3 \%$ were performed face to face and $10.7 \%$ by telephone. No difference was found in the rate of GAD in those assessed by these two methods. The mean age ( \pm S.D.) of the sample at interview was $30.1 \pm 7.6$. Zygosity was determined by the use of standard self-report questions, photographs, and when uncertain, genotyping by DNA polymorphisms. Final zygosity diagnoses yielded $590 \mathrm{MZ}, 440 \mathrm{DZ}$ and 3 pairs of unknown zygosity.

\section{MEASURES, INTERVIEWERS AND DIAGNOSTIC REVIEW}

A lifetime diagnosis of GAD was made using an adaptation of an early version of the Structured Clinical Interview for DSM-III-R Diagnosis (SCID; Spitzer et al., 1987), a reliable instrument for the diagnosis of GAD (Riskind et al., 1987). This adaptation differed from current versions of the SCID in three significant ways. First, the introductory question was modified to inquire about periods of at least one rather than six months in duration. Second, no question inquired whether the anxiety or worry affected two or more life circumstances. Third, the SCID item inquiring about one of the 18 symptomatic criteria for GAD (\#11, "flushes or chills") was inadvertently left off the interview, reducing the total number of symptomatic criteria from 18 to 17 .

The lifetime diagnosis of GAD was based on a blind review by K.S.K., an experienced psychiatric diagnostician, using DSM-III-R criteria (American Psychiatric Association, 1987), except that the required minimum duration of illness was reduced from six months to one month and issues of diagnostic hierarchy were ignored. GAD was not diagnosed when the symptoms were considered due to medical illness or medication. In addition, lifetime diagnoses were made using DSMIII-R criteria for panic disorder, major depression, al- cohol dependence, anorexia nervosa and bulimia nervosa. With two exceptions, we applied, for these diagnostic categories, unmodified DSM-III-R criteria. For bulimia, we included "subsyndromal" bulimic-like syndromes because in this sample they closely resembled, from both an epidemiologic and a genetic perspective, those cases meeting full DSM-III-R criteria (Kendler et al., 1991). Phobia was defined as the presence of one or more irrational fears that objectively interfered in the respondent's life. Based on the approach used by Leckman et al. (1983) in a study of major depression, probands with GAD with a lifetime diagnosis of major depression or panic disorder are divided into those where the disorders were always associated with GAD episodes (here termed contemporaneous comorbid cases) and those that were, at least some of the time, separate from the GAD episodes (here termed non-contemporaneous comorbid cases).

All interviewers, who underwent extensive and ongoing training during the field study, had a minimum of either a Master's degree in Psychology or Social Work or a Bachelor's degree and at least two years clinical experience. The same interviewer never interviewed both members of a twin pair.

If a twin answered positively to the "stem" question for GAD on the SCID, and answered positively to at least five of the symptomatic criteria, then she was asked three additional questions about her episodes of GAD including: (1) age at first episode, (2) total number of episodes, and (3) length of longest episode.

Inter-rater reliability was assessed in 53 jointly conducted interviews. Each of these interviews was blindly reviewed and the percent agreement and chance corrected agreement (Cohen, 1960) for the diagnosis of GAD was $91 \%$ and $+0.77 \pm 0.10(p<0.001)$, respectively.

\section{TREATMENT OF INDIVIDUAL SYMPTOMS}

While it would be of interest to determine the relationship between each individual symptom and risk for GAD in the co-twin, the performance of 17 separate tests would introduce an unacceptably high probability of a spurious positive finding. Therefore, for the purpose of data reduction, we submitted a productmoment correlation matrix for all 17 symptoms to a factor analysis and VARIMAX rotation (SAS Institute, 1985; results available on request). Three factors were identified and (along with the items with the heaviest loading, all positive), in descending order, were as follows: autonomic hyperactivity (shortness of breath, palpitations, dizziness, feeling shaky and sweating), hypervigilance (trouble concentrating, trouble sleeping, exaggerated startle, irritability, muscle tension and keyed up) and gastrointestinal symptoms (dry mouth, frequent urination, restlessness, upset stomach and lump in throat). "Easy fatigability" did not load distinctly on any three of these factors. Similar factors were obtained if the factor analysis was conducted using tetrachoric correlations. Factor scores for these three factors were used in subsequent analyses. 


\section{STATISTICAL ANALYSIS}

Since our goal was to examine the relationship between clinical characteristics of GAD in affected twins and the risk for GAD in their co-twins, our analysis focused on pairs of observations: a proband twin with GAD and her co-twin. Twin pairs where neither had a lifetime diagnosis of GAD were, per force, excluded from the analysis. The remaining pairs could be divided into two groups: (1) pairs where only one twin had GAD, which are "counted" once in our analysis, and (2) pairs where both twins had GAD, which are "counted" twice in our analysis.

Since GAD has an age-dependent onset and our sample is variable with respect to age, we utilized the Cox proportional hazard model, as operationalized in the PHGLM procedure in SAS (SAS Institute, 1986). In the Cox model, the dependent variable is the hazard rate for GAD, defined as the risk for a previously unaffected twin to develop GAD in a given unit of time, here a year. A twin with no lifetime diagnosis of GAD is retained in the analysis until her current age, at which point she is "censored" (i.e., removed) from the analysis.

Although "double" counting twins from concordant pairs does not result in a bias in parameter estimation (McGue et al., 1984), some correction is required for incorrectly assuming the independence of the observations from these doubly counted twin pairs $(n=83)$. If $\mathrm{T}$ is the total number of observations, $\mathrm{N}$ the number of doubly counted twin pairs, and $\mathrm{P}$ the number of parameters in our model, we multiplied the standard errors obtained by $[(\mathrm{T}-\mathrm{P}) /(\mathrm{T}-\mathrm{N}-\mathrm{P})]^{1 / 2}$. Although approximate, this correction is likely to be conservative (Kish and Frankel, 1974). All significances reported are based on our corrected standard errors. In the stepwise proportional hazard model, we used entry and exit criteria of 0.50 and 0.10 , respectively. For all analyses, we utilized the traditional $p \leq .05$ criterion for significance. All $\chi^{2}$ analyses from the Cox analyses have one degree of freedom.

We wanted in all our analyses to control for two variables: zygosity and year of birth. Zygosity was included to control for the higher risk observed in $\mathrm{MZ}$ vs. DZ co-twins of affected twins (Kendler et al., 1992a). Year of birth was included to control for any possible cohort effect for GAD. Probandwise concordance, tetrachoric correlations and biometrical model fitting for GAD in this sample have been reported previously (Kendler et al., 1992b).

\section{RESULTS CHARAC'TERISTICS OF THE SAMPLE}

Clinical Features. Key clinical characteristics of the 486 twins with GAD, who had a mean age $( \pm$ S.D.) at interview of $28.7 \pm 9.0$, are seen in Table 1. This sample had a mean and median number of episodes of 4.2 and 2, respectively. The mean and median dura-
TABLE 1. Clinical features of GAD in the proband twin that predict risk for GAD in the co-twin ${ }^{a}$

\begin{tabular}{|c|c|c|c|}
\hline Variable & Mean \pm S.D. & $\chi^{2}$ & $p$ \\
\hline Age at onset & $22.5+8.5$ & 0.00 & 0.957 \\
\hline $\begin{array}{l}\text { Number of } \\
\text { symptomatic criteria }\end{array}$ & $9.3 \pm 2.9$ & 18.58 & 0.000 \\
\hline $\begin{array}{l}\text { Maximum duration } \\
\text { (weeks) }\end{array}$ & $29.4 \pm 78.9$ & 0.02 & 0.886 \\
\hline Number of episodes & $4.2 \pm 9.8$ & 5.20 & 0.022 \\
\hline
\end{tabular}

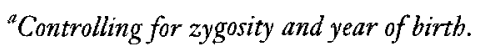

tion of the longest episode of illness was 29.4 and 9 weeks, respectively. The mean and median number of total endorsed symptoms was 9.3 and 9, respectively.

Comorbidity. The proportion of twins meeting criteria for GAD who also made criteria for a lifetime diagnosis of the other assessed psychiatric disorders is seen in Table 2 and ranged from $1.6 \%$ for anorexia nervosa to $48.5 \%$ for phobia. The proportion of twins with GAD who met criteria for major depression and panic disorder only during episodes of GAD was 23.7 and $3.3 \%$, respectively.

\section{PREDICTION OF RISK FOR GAD IN THE CO-TWIN: VARIABLES TAKEN ONE AT A TIME}

Clinical Features. The relationship between the clinical characteristics of GAD in the proband and the risk for GAD in the co-twin, as assessed by the Cox Proportional Hazard model, controlling for zygosity and year of birth, is presented in Table 1. Both the number of endorsed symptomatic criteria and the total number of episodes significantly predicted an increased risk for GAD in the co-twin $(p=0.000$ and 0.022 , respectively). However, neither age at onset of GAD nor maximum duration of an episode bore any relationship to the risk for GAD in the co-twin.

Comorbidity. The impact of comorbidity, taken one disorder at a time, on the risk for GAD in the cotwin is seen in Table 2. While the co-occurrence in the proband twin of any disorder increased the risk for

TABLE 2. Comorbidity as a predictor of risk for GAD in the co-twin ${ }^{a}$

\begin{tabular}{lcccc}
\hline Disorder & Kind & Frequency (\%) & $\chi^{2}$ & $p$ \\
\hline Major depression & $\mathrm{NC}^{\mathrm{b}}$ & 45.1 & 0.19 & .662 \\
Major depression & $\mathrm{C}^{\mathrm{b}}$ & 23.7 & 0.64 & .423 \\
Panic disorder & $\mathrm{NC}$ & 13.0 & 4.89 & .029 \\
Panic disorder & $\mathrm{C}$ & 3.3 & 0.31 & .576 \\
Phobia & LT & 48.5 & 0.87 & .351 \\
Alcohol dependence & $\mathrm{LT}$ & 12.8 & 1.82 & .177 \\
Bulimia & $\mathrm{LT}$ & 9.7 & 4.28 & .039 \\
Anorexia & $\mathrm{LT}$ & 1.6 & 0.09 & .760 \\
\hline
\end{tabular}

${ }^{a}$ Controlling for zygosity and year of birth.

${ }^{b} \mathrm{NC}$, noncontemporaneous; $C$, contemporaneous; LT, lifetime. 
GAD in the co-twin, this effect was statistically significant only for non-contemporaneous panic disorder and bulimia ( $p=0.029$ and 0.039 , respectively).

Symptoms. Controlling for zygosity and year of birth, autonomic hyperactivity $\left(\chi^{2}=4.66, p=0.031\right)$, and hypervigilance $\left(\chi^{2}=9.72, p=0.002\right)$ significantly and positively related to the risk of $\mathrm{GAD}$ in the cotwin, while the results for gastrointestinal symptoms were nearly significant $\left(\chi^{2}=3.54, p=0.060\right)$. Since total number of endorsed symptoms was strongly related to risk for GAD in the co-twin, we repeated the analysis of the symptom factors, controlling for the total number of endorsed symptoms. In these analyses, none of the symptom factors any longer significantly predicted risk of GAD in the co-twin: autonomic hyperactivity $\left(\chi^{2}=1.09, p=0.297\right)$, hypervigilance $\left(\chi^{2}=\right.$ $1.00, p=0.317)$ and gastrointestinal symptoms $\left(\chi^{2}=\right.$ $0.01, p=0.939$ ).

\section{PREDICTION OF RISK FOR GAD IN THE CO-TWIN: MULTIVARIATE ANALYSIS}

Finally, we conducted a stepwise proportional hazards regression that began with all the variables previously considered. Only two variables uniquely predicted the risk of GAD in the co-twin: total number of symptoms $\left(\chi^{2}=18.60, p=0.000\right)$ and comorbidity with bulimia nervosa $\left(\chi^{2}=4.33, p=0.038\right)$. (The third variable entered into the stepwise regression, total number of episodes, was accepted into the model but then rejected because its $p$ value, 0.184 , exceeded 0.10 .) Doing a median split, the relative risk for GAD in the cotwin of proband twins with $\leq 9$ vs. $>9$ endorsed symptoms was 1.72 . The relative risk tended to increase if the threshold for number of symptoms increased: $\leq 10$ vs. $>10-1.68, \leq 12$ vs. $>12-1.89$, $\leq$ 14 vs. $>14-2.52$ and $\leq 16$ vs. $>16-5.46$. The relative risk for GAD in the cotwins of proband twins with versus without a diagnosis of bulimia nervosa was 1.69 .

\section{DISCUSSION}

We found that it was possible to relate clinical and etiologic heterogeneity in GAD. Individuals with a high familial vulnerability to GAD, as reflected by the risk for GAD in their co-twins, systematically differed in certain of their clinical characteristics from twins with a low familial vulnerability.

The strongest unique predictor of risk of illness in relatives was the number of endorsed symptoms. In GAD, an individual's familial vulnerability to illness is apparently indexed by the number of symptoms experienced and reported. These results are in striking contrast to a parallel analysis in this same data set of major depression (Kendler et al., 1994) in which the number of endorsed symptoms was unrelated to the risk for depression in the co-twin. Unlike with major depression, our findings suggest that the validity of the GAD syndrome, from a familial perspective, might be increased if a larger number of symptoms were required to meet diagnostic criteria.

The other unique predictor of risk for GAD in relatives was lifetime comorbidity with bulimia. The same result occurred in our parallel analysis of major depression in this sample (Kendler et al., 1994), suggesting that bulimia in women may reflect a high familial vulnerability to several inter-related psychiatric syndromes.

Length of longest episode of GAD was unrelated to the risk for GAD in the co-twin. From a familial perspective, a longer minimum duration of GAD does not appear to increase the validity of the diagnostic category. These results do not support the substantial prolongation of the minimal duration of a GAD episode from one month in DSM-III to six months in DSM-III-R and DSM-IV.

Number of episodes significantly predicted the risk for GAD in the co-twin, but when other factors were controlled for, this result lost significance. These results suggest that recurrence in GAD is not as good an index of familial vulnerability to this illness as it is for major depression (Gershon et al., 1986; Bland et al., 1986; Kendler et al., 1994).

We were unable to find evidence that GAD presenting largely with somatic versus psychic symptoms (Hoehn-Saric et al., 1989) differed in familial vulnerability. Controlling for the total number of endorsed symptoms, the number of hypervigilant vs. autonomic hyperactivity items endorsed did not significantly relate to the risk for GAD in the co-twin. It may still be possible that in pairs of concordant twins, members resemble one another in their GAD symptom profiles. This question will be addressed in subsequent analyses.

Age at onset of GAD also was unrelated to the risk of illness in the co-twin. Early age at onset has been associated with increased familial vulnerability to illness for several neuropsychiatric disorders including Alzheimer's disease (Heston et al., 1981), alcoholism (Goodwin, 1984) and, in most studies, affective illness (Weissman et al., 1984). If our finding is confirmed, it suggests that age at onset of GAD may be influenced primarily by non-familial factors, which could include environmental stressors.

When using a one-month minimum duration of illness, GAD is quite a common disorder in the general population (Breslau and Davis, 1985; Wells et al., 1989; Robins and Regier, 1991; Kendler et al., 1992b). If the goal is to produce a GAD syndrome that is less common, our results suggest that, from a familial perspective, it will be more valid to increase the minimum number of required symptoms than to increase the required duration beyond the one month proposed in DSM-III.

\section{LIMITATIONS}

Our results should be interpreted in the context of three potential limitations. First, our results are relevant only for females. Although little is known about 
gender differences in the familial influences on GAD, given the known differences in prevalence of anxiety disorder in men and women (Robins and Regier, 1991; Wells et al., 1989), it is possible that the familial vulnerability to GAD may manifest differently across sexes.

Second, as outlined above, the diagnostic criteria for GAD assessed in this study included most, but not all, of those included in the final version of DSM-III-R (American Psychiatric Association, 1987), the most significant change being a reduction in the minimum duration of illness from six to one month. We did not attempt analyses with " 6 -month" GAD, because of previous experience in this data set that this disorder was too rare to provide stable statistical estimates (Kendler et al., 1992b).

Third, in this report, we related the clinical characteristics of GAD to the tendency for GAD to aggregate in families. We have previously shown in this sample that the familial aggregation of GAD can be best explained as a result solely of genetic factors (Kahn et al., 1986). Therefore, the indices of familial GAD found in this report probably reflect the genetic, and not just the familial, liability to GAD. While it would have been desirable to demonstrate this directly, the class of analyses reported here cannot currently be performed with the more appropriate sophisticated methods, in large part because of the problems of multi-dimensional integration (Neale et al., 1989; Kendler et al., 1994). A more definitive resolution of the issues addressed in this report must await the availability of such models.

Acknowledgments. This work was supported by grants MH-40828 and MH/AA 49492 from the United States National Institutes of Health. The Virginia Twin Registry, established and maintained by W. Nance, M.D., Ph.D. and L. Corey, Ph.D., is supported by the United States National Institutes of Health grants HD-26746 and NS-31564. Leroy Thacker, M.S., assisted in the data analyses.

\section{REFERENCES}

American Psychiatric Association (1980) Diagnostic and Statistical Manual of Mental Disorders, Third Edition. Washington, DC: American Psychiatric Association.

American Psychiatric Association (1987) Diagnostic and Statistical Manual of Mental Disorders, Revised Third Edition. Washington, DC: American Psychiatric Association.

American Psychiatric Association (1994) Diagnostic and Statistical Manual of Mental Disorders, Fourth Edition. Washington, DC: American Psychiatric Association.

Barlow DH, Blanchard EB, Vermilyea JA, Vermilyea BB, DiNardo PA (1986) Generalized anxiety and generalized anxiety disorder: Description and reconceptualization. Am J Psychiatry 143:40-44.

Bland RC, Newman SC, Orn H (1986) Recurrent and nonrecurrent depression: A family study. Arch Gen Psychiatry 43:1085-1089.

Breier A, Charney DS, Heninger GR (1985) The diagnostic validity of anxiety disorders and their relationship to depressive illness. Am J Psychiatry 142:787-797.
Breslau N, Davis GC (1985) DSM-III generalized anxiety disorder: An empirical investigation of more stringent criteria. Psychiatry Res 14:231-238.

Breslau N, Davis GC, Prabucki K (1987) Searching for evidence on the validity of generalized anxiety disorder: Psychopathology in children of anxious mothers. Psychiatry Res 20:285-297.

Brown TA, Barlow DH, Liebowitz MR (1994) The empirical basis of generalized anxiety disorder. Am J Psychiatry 151:1272-1280.

Cohen J (1960) A coefficient of agreement for nominal scales. Educ Psychol Meas 20:37-46.

Gershon ES, Weissman MM, Guroff JJ, Prusoff BA, Leckman JF (1986) Validation of criteria for major depression through controlled family study. J Affective Disord 11:125-131.

Goodwin DW (1984) Studies of familial alcoholism: A review. J Clin Psychiatry 45:14-17.

Heston LL, Mastri AR, Anderson VE, White J (1981) Dementia of the Alzheimer type: Clinical genetics, natural history and associated conditions. Arch Gen Psychiatry 38:1085-1090.

Hoehn-Saric R, McLeod DR, Zimmerli WD (1989) Symptoms and treatment responses of generalized anxiety disorder patients with high versus low levels of cardiovascular complaints. Am J Psychiatry 146:854-859.

Kahn RJ, McNair DM, Lipman RS, Covi L, Rickels K, Downing R, Fisher S, Frankenthaler LM (1986) Imipramine and chlordiazepoxide in depressive and anxiety disorders. II. Efficacy in anxious outpatients. Arch Gen Psychiatry 43:79-85.

Kendler KS, MacLean CJ, Neale MC, Kessler RC, Heath AC, Eaves LJ (1991) The genetic epidemiology of bulimia nervosa. Am J Psychiatry 148:1627-1637.

Kendler KS, Neale MC, Kessler RC, Heath AC, Eaves LJ (1992a) A population based twin study of major depression in women: The impact of varying definitions of illness. Arch Gen Psychiatry 49:257-266.

Kendler KS, Neale MC, Kessler RC, Heath AC, Eaves LJ (1992b) Generalized anxiety disorder in women: A population based twin study. Arch Gen Psychiatry 49:267-272.

Kendler KS, Neale MC, Kessler RC, Heath AC, Eaves LJ (1994) The clinical characteristics of major depression as indices of the familial risk to illness. Brit J Psychiatry 165:66-72.

Kish L, Frankel MR (1974) Inferences from complex samples. J Roy Stat Soc, Ser B 36:1-37.

Leckman JF, Merkangas KR, Pauls DL, Prusoff BA, Weissman MM (1983) Anxiety disorders and depression: Contradictions between family study data and DSM-III conventions. Am J Psychiatry 140:880-882.

McGue R, Wette R, Rao DC (1984) Evaluation of path analysis through computer simulation: Effects of incorrectly assuming independent distribution of familial correlations. Genet Epidemiol 1:255-269.

Neale MC, Eaves LJ, Hewitt JK, Meyer JM, Kendler KS (1989) Analyzing the relationship between age at onset and risk to relatives. Am J Hum Genet 45:226-239.

Riskind JH, Beck AT, Berchick RJ, Brown G, Steer RA (1987) Reliability of DSM-III diagnoses for major depression and generalized anxiety disorder using the Structured Clinical Interview for DSM-III. Arch Gen Psychiatry 44:817-820.

Robins E, Guze SB (1970) Establishment of diagnostic validity in psychiatric illness: Its application to schizophrenia. Am J Psychiatry 126:983-987.

Robins LN, Regier DA, eds. (1991) Psychiatric Disorders in America. New York: The Free Press.

SAS Institute (1985) SAS User's Guide: Statistics, Version 5. Cary, NC: SAS Institute, Inc.

SAS Institute (1986) SUGI Supplemental Library User's Guide, Version 5 Edition. Cary, NC: SAS Institute, Inc. 
Spitzer RL, Endicott J, Robins E (1975) Research Diagnostic Criteria for a Selected Group of Functional Disorders. 2nd ed. New York: New York Psychiatric Institute.

Spitzer RL, Williams JB, Gibbon M (1987) Structured Clinical Interview for DSM-III-R. New York: Biometrics Research Dept, New York State Psychiatric Institute.

Weissman MM, Wickramaratne P, Merikangas KR, Leckman JF,
Prusoff BA, Caruso KA, Kidd KK, Gammon D (1984) Onset of major depression in early adulthood: Increased familial loadings and specificity. Arch Gen Psychiatry 41:1136-1143.

Wells JS, Bushnell JA, Hornblow AR, Joyce PR, Oakley-Browne MA (1989) Christchurch psychiatric epidemiology study, part I: Methodology and lifetime prevalence for specific psychiatric disorders. Aust N Z J Psychiatry 23:315-326. 